\title{
Fossil Fuel Extraction and Investment in Backstop Technology: A Strategic Interaction
}

\author{
Hamideh Esfahani ${ }^{1}$ \\ Seyedeh Shiva Shahmiri²
}

| h.esfahani@imps.ac.ir

\begin{abstract}
In the economy of renewable resources, oil-importing countries seek to explore and develop backstop technologies to moderate their reliance on oil suppliers. On the other hand, oil-exporting countries should integrate the possibility of backstop technology inventions in their decisions regarding oil supply. Therefore oil-exporting countries and oilimporting-countries essentially have a relationship in the form of strategic interdependence. The present study considers a dynamic game between a buyer and a seller, where the seller determines the supply quantity and the buyer can decide to invest in a substitute which is a renewable source that is more favorable for both the buyer and the environment. The results show that in this closed-loop equilibrium, due to the heterogeneity between the fuel supplied by the seller and the alternative fuel developed by the buyer, the time of investing depends on the investment cost and the positive impact of substitute fuel on the environment. Nevertheless, the time of investing is more likely to occur before the resource exhaustion.
\end{abstract}

Keywords: Fossil Fuel, Backstop Technology, Strategic Interaction, Dynamic Competition, Closed-loop Equilibrium.

JEL Classification: C72, Q30, O30.

1. Assistant Professor of Economics, Institute for Management and Planning Studies, Tehran, Iran, (Corresponding Author).

2. M.A. in Socio-Economic System Engineering, Institute for Management and Planning Studies, Tehran, Iran. 


\section{استخراج منابع فسيلى و سرمايلَذارى سوخت جايخزين: يك تعامل راهبر الهي في}

h.esfahani@imps.ac.ir

مقاله بزوهشى
حميده اصفههانى

استاديار اقتصاد موسسه عالى آموزش و يزوهش مديريت

و برنامهريزى، تهران (نويسنده مسئول).

سيده شيوا شاهميرى

كارشناسى ارشد سيستمهاى اقتصادى اجتماعى، موسيه

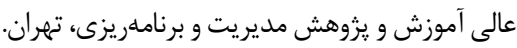

يذيرش: و

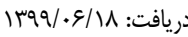

קُكيده: در اقتصاد منابع تجديدنايذير، كشورهاى واردكننده براى كاهش وابستخى به عرضه كنند

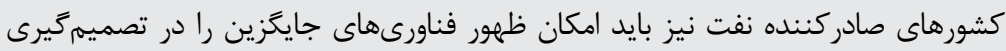

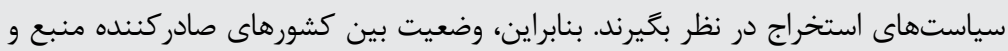

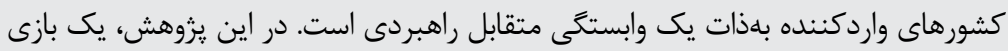

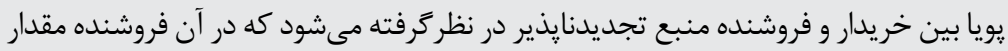

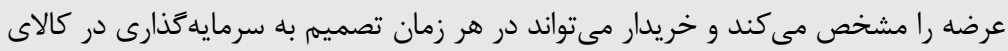

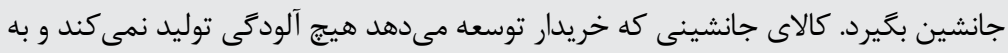

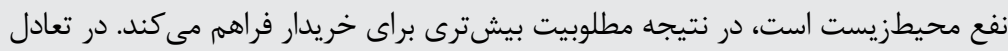

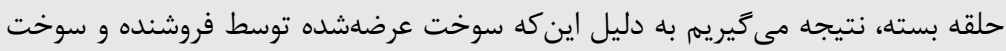

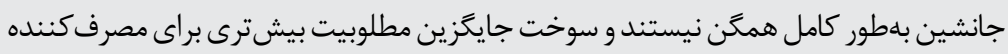

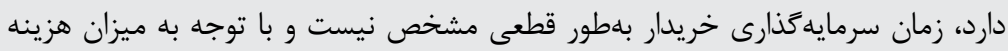

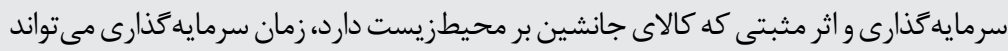

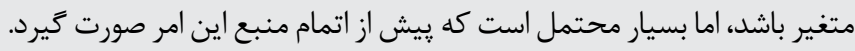

كليدوازهها: سوخت فسيلى، فناورى پشتيبان، تعامل راهبردى، رقابت يويا، تعادل حلقه بسته. طبقهبندى O30, Q30, C72 :JEL. 


\section{مقدمه}

كشورهاى صادركننده نفت براى اين كه وابستكى كشورهاى مصرفكننده را به خودشان بيشتر

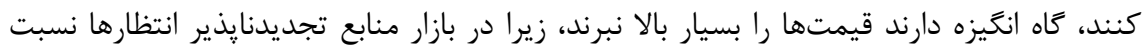

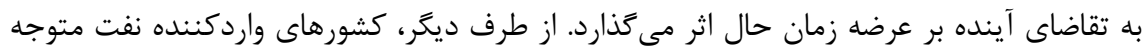
هستند كه سرمايهگذارى در ساير منابع انرزى نهتنها يك راه براى مقابله با كميابى فيزيكى نفت است، بلكه بر تصميمهاى عرضه كشورهاى صادركننده تاثير مى كذارد. وقتى كه خريدار در اولين دوره، زمان نهان رسيدن كالاى جانشين را مشخص كند، نهتنها شرايط بازار هنگام ورود كالاى جانشين تغيير مى كند، بلكه مسير عرضه در تمام دورههاى قبلى را تحت تاثير قرار مىدهد. با كذر زمان، وقتى كه عرضه در

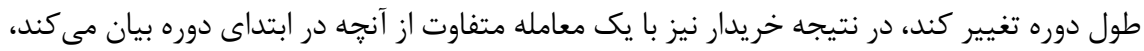

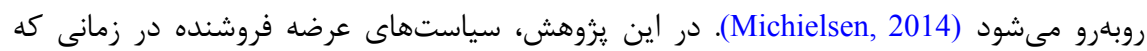

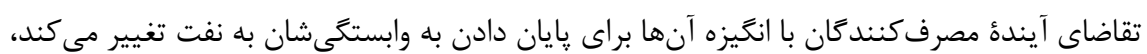

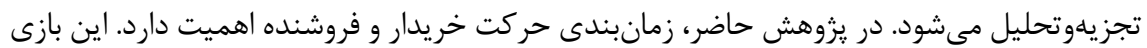

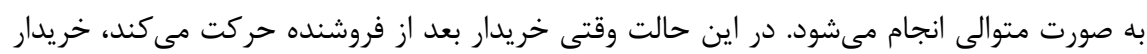

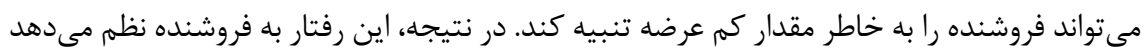

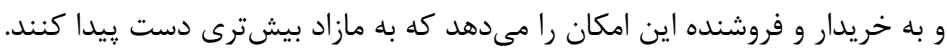

\section{مبانى نظرى يخوهش}

يكى يرسش اساسى در اقتصاد منابع تجديدنايذير مربوط به انخَيزها براى كشف فناورى يشتيبان تجديديذير براى جايكزينى منابع طبيعى محدود است كه در حال تخليه شدن است. كشورهاى

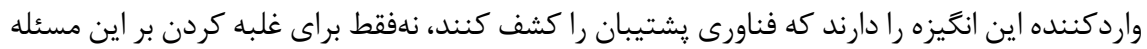
كه منابع محدود هستند، بلكه براى اينكه وابستخى خودشان را به توليدكنندكان منبع، كه اغلب

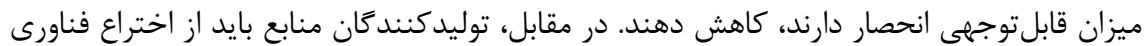

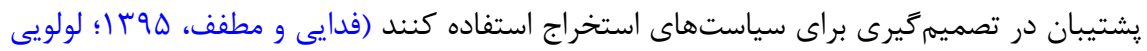

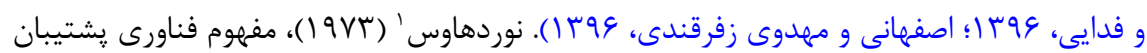
را معرفى مى كند و زمان ورود اين فناورى را در بازارهايى كه عرضه محدود دارند، تجزيلوتحليل 
مى كند. فناورى يشتيبان به اين صورت تعريف مىشود كه فناورى يشتيبان يك جايكزين مناسب

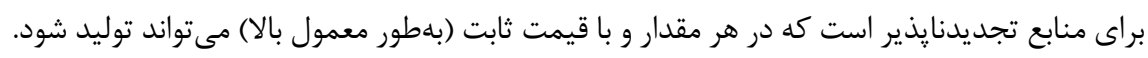

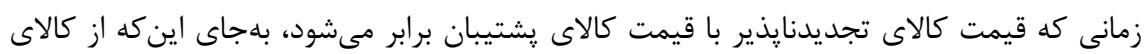

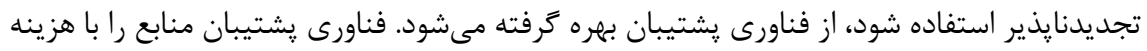

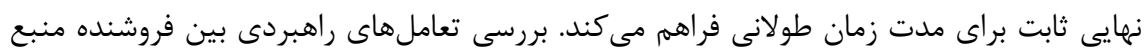

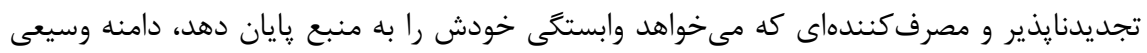

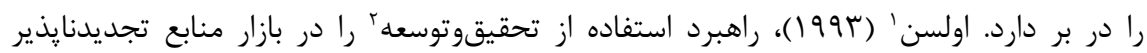

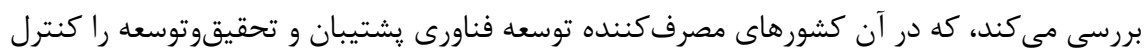

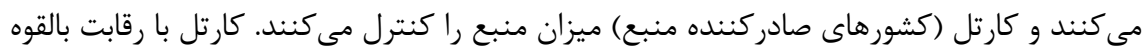

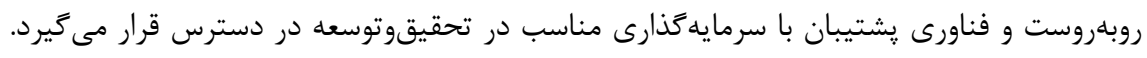

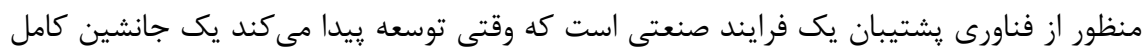

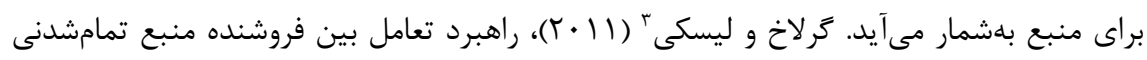

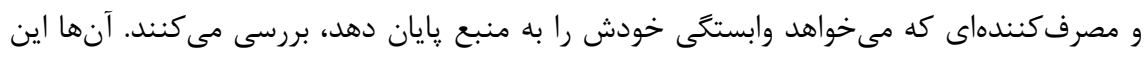

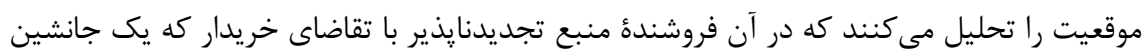

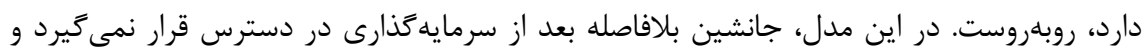

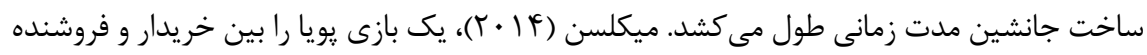

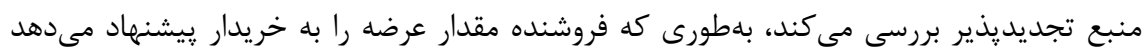

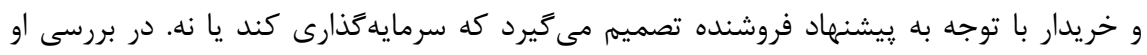

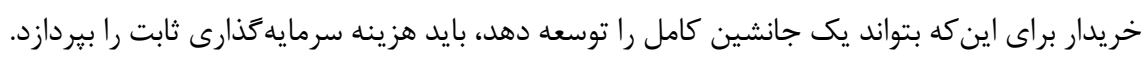

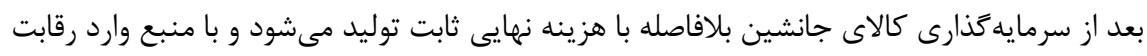

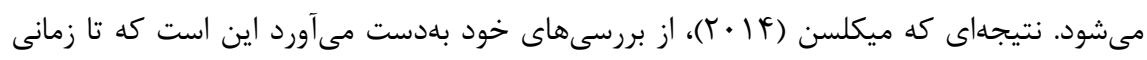

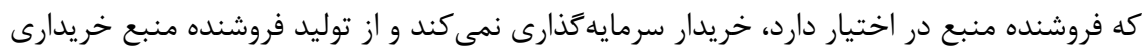

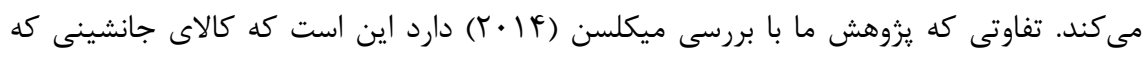

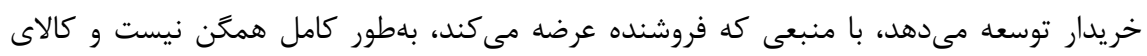

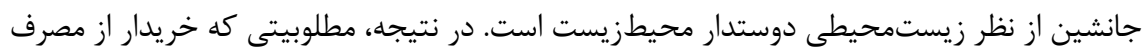

\section{Olsen}

2. Research \& Development (R\&D)

3. Gerlagh \& Liski 
كالاى خود مىبرد بيشتر از مطلوبيتى است كه از مصرف منبعى كه فروشنده عرضه مى كند، بلهست

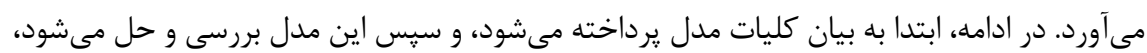
و نتايج آن ارائه مى كردد.

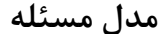

در اين يزوهش، مدلى با يك خريدار و يك فروشنده منبع تجديدنايذير در نظرگرفته مىشود. فروشنده منبع كشورهاى صادركننده نفت هستند كه در هر دوره مقدارى از منبع در اختيار را عرضه مى كنند. خريدار نيز كشورهاى مصرفكننده هستند كه در هر دوره تصميم مى گيرند از فروشنده خريدارى كنند يا اين كه در فناورى پشتيبان سرمايهُذارى كنند و كالاى جانشين را توسعه دهند.'

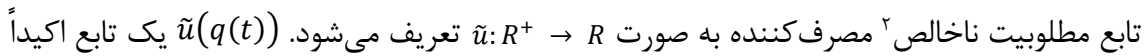

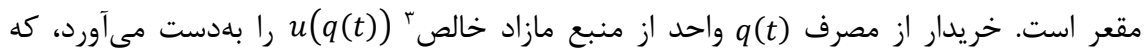

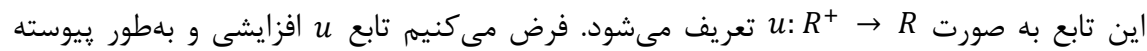

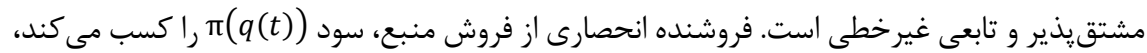
كه اين تابع به صورت

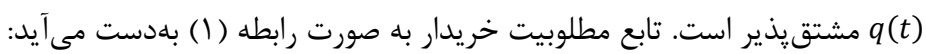

$u_{i}=\left(1+\alpha_{i}\right) \tilde{u}-p q$

كه در آن b, خريدار توليد مى كند. به عبارت ديكر، us مطلوبيتى است كه خريدار از مصرف منبعى كه فروشنده عرضه مى كند، بهدست مى آورد. un مطلوبيتى است كه خريدار از مصرف كالايى كه خودش توليد

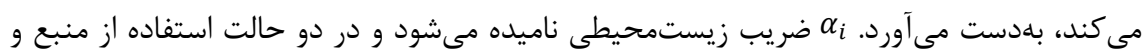
استفاده از كالاى جانشين متفاوت است و به صورت رابطه (rا) تعريف مىشود:

2. Gross Utility

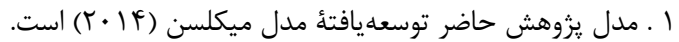

3. Net Surplus 


$$
\left\{\begin{array}{l}
\alpha_{s}=0, \forall q_{s} \\
\alpha_{b}=\alpha, \forall q_{b}
\end{array}\right.
$$

كه $\alpha_{s}$ استفاده از كالاى جانشينى است كه خريدار توسعه مى دهد و 1 > >

$$
\begin{aligned}
& u_{i}=\left(1+\alpha_{i}\right) \tilde{u}-p q \\
& \frac{\partial u_{i}(q(t))}{\partial q(t)}=0 \rightarrow \frac{\partial u_{i}}{\partial q(t)}=\left(1+\alpha_{i}\right) \widetilde{u^{\prime}}-p=0 \rightarrow p=\left(1+\alpha_{i}\right) \widetilde{u^{\prime}}(q(t))
\end{aligned}
$$

در نتيجه، تابع تقاضاى عقبَرد، براى حالتى كه مصرفكننده از منبع فروشنده خريدارى كند، به صورت رابطه (ه) است:

$$
p_{s}=\widetilde{u^{\prime}}(q(t))
$$

و اگر مصرفكننده از سوخت جايكزين، كه خريدار توسعه مىدهد، استفاده كند تابع تقاضاى عقبر

$p_{b}=(1+\alpha) \tilde{u^{\prime}}(q(t))=c$

$$
u_{i}(q(t))=\left(1+\alpha_{i}\right) \tilde{u}(q(t))-\tilde{u}^{\prime}(q(t))\left(1+\alpha_{i}\right) q(t)
$$

فروشنده انحصاركر منبع محدود s s را دارد و در اين مدل فرض مى كنيم استخراج بدون هزينه در نظر گرفته مىشود. هدف فروشنده اين است كه مجموع جريان تنزيل شده سود آنى را بيشينه كند. تابع سود فروشنده به صورت رابطه (^) است:

$$
\pi(q(t))=\widetilde{u}^{\prime}(q(t)) q(t)
$$

تابع مطلوبيت و سود با نرخ r تنزيل مىشوند. خريدار مىتواند بلافاصله براى منبع يك جانشين

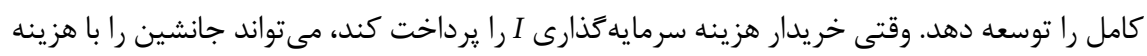
نهايى ثابت c ت توليد كند.

\section{زمانبندى تعامل بين فروشنده و خريدار}

در اين يزوهش، زمانبندى حركت خريدار و فروشنده اهميت دارد. اين بازى به صورت متوالى

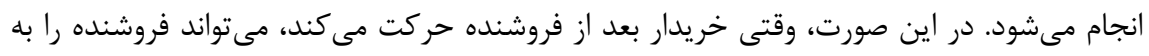


خاطر مقدار كم عرضه تنبيه كند. در نتيجه، اين رفتار به فروشنده نظم مى دهد و به خريدار و فروشنده

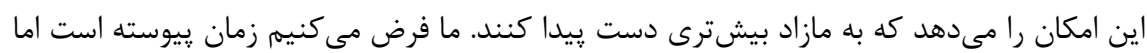

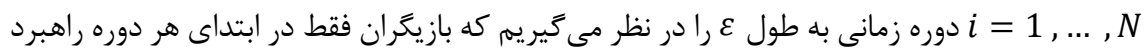

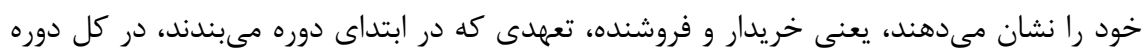

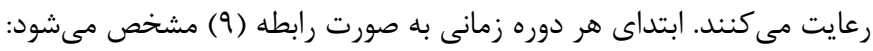

$t_{i}=\varepsilon(i-1)$

ما در اين يزوهش زمان را به دو بخش تقسيم مى كنيم، دوره قبل از سرمايه كذارى را با فاز A و

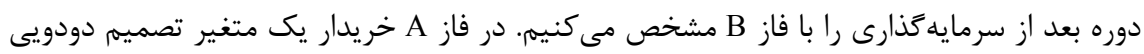
$k\left(t_{i}\right) \in\{0,1\}$ سوخت جايگزين كند، در فاز A هر دوره سه مرحله دارد: فروشنده مقدار عرضه

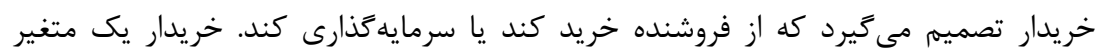
$k\left(t_{i}\right) \in\{0,1\}$ تصميم دودويى دارد كه: اگر $k\left(t_{i}\right)=0$ باشد، خريدار سرمايهگذارى نمى كند. با قيمت $p\left(t_{i}\right)=\tilde{u^{\prime}}$ مبادله بين خريدار و فروشنده انجام مىشود. اگر سرمايه گذارى مى كند. فروشنده در مقدار رِيشنهادى (t) مبادله بين خريدار و فروشنده انجام مىشود. $P\left(t_{i}\right)=\min \left(\widetilde{u^{\prime}}\left(q^{\prime}\left(t_{i}\right)\right), f(\alpha) c\right)$

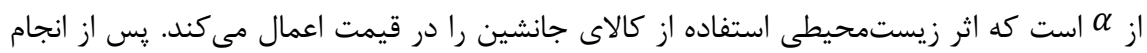
سرمايهَذارى وارد فاز B مىشويم. در فاز B سرمايهَذارى انجام مىشود و فروشنده مقدار (t) را انتخاب مى كند و با قيمت فرض مى كنيم كه سرمايه گذارى انجام مىشود، و ابتدا فاز B را محاسبه مى كنيم كه در آن خريدار و فروشنده عوايدشان را محاسبه مى كنيند. 
فاز بعد از سرمايهخذارى

اين بازى به روش استدلال عقبَرد حل مىشود. به اين شكل كه از مرحله آخرِ بازى شروع مىشود

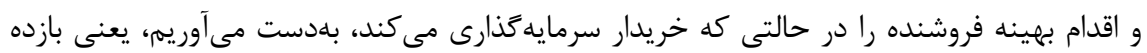
هر يك از بازيكنان را در فاز B محاسبه مى كنيم. سيس به سراغ مرحله قبل از سرمايهگذارى مىرويم و با توجه به اقدام بهينه مرحله بعد از سرمايهگذارى، تعادل اين مرحله را نيز ميى يابيهم. وقتى خريدار

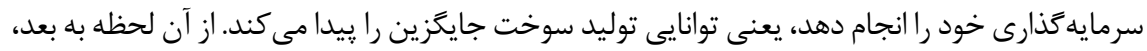
هيج عامل ديكرى نمى تواند اثر بخذارد. اين بازى مى تواند تا بىنهايت بر اساس زمان جلو برود، به همين

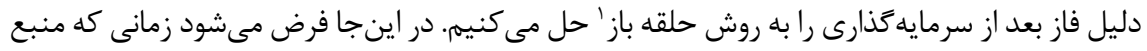

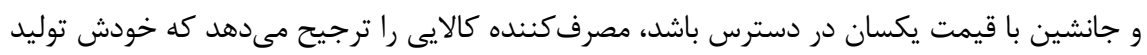

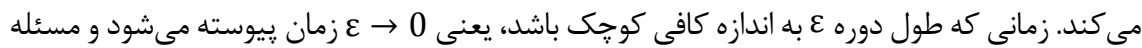

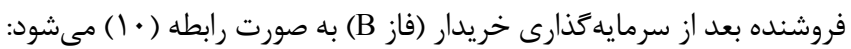
$\max _{q} \int_{0}^{\infty}(p q) e^{-r t} d t=\max _{q} \int_{0}^{\infty} \min \left(\tilde{u}^{\prime}\left(q_{t_{i}}\right), f(\alpha) c\right) q\left(t_{i}\right) e^{-r t} d t$

s.t. $\quad \dot{s}=-q(t)$

$s(t) \geq 0$

$$
q(t) \geq 0
$$

$s_{0}$ given

براى حل مسئله كنترل بهينه، از روش اصل بيشينهسازى پپنترياگين` استفاده مىشود. تابع هميلتونى اين مسئله به صورت رابطه (1) (1) است:

$H(q, s, \lambda)=\min \left(\tilde{u}^{\prime}\left(q\left(t_{i}\right)\right), f(\alpha) c\right) q\left(t_{i}\right)-\lambda(t) q\left(t_{i}\right)$

شرط مرتبه اول ب به صورت رابطه (r (I) است:

$\frac{\partial H}{\partial q} \leq 0 \rightarrow \pi^{\prime}(q(t))-\lambda(t) \leq 0 \quad L \quad q(t) \geq \tilde{u}^{\prime-1}\left(\frac{c}{1+\alpha}\right)$

معادله الحاقى

$\dot{\lambda}=r \lambda(t)$

1. Open-Loop

2. Pontryagin Maximum Principle

$\Delta q$
3. First Order Condition

4. Adjoint Equation 


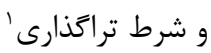

$\lim _{t \rightarrow T} \lambda(t) s(t)=0$

كه در آن آل ارزش كمبود منابع يا همان قيمت سايهاى؟ است. درآمد نهايى به صورت رابطه

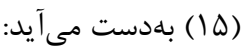

$\pi^{\prime}(q(t))=\left\{\begin{aligned} \tilde{u}^{\prime}(q(t))+q(t) \tilde{u}^{\prime \prime}(q(t)), & q(t) \\ f(\alpha) c, q(t) & <q^{*}\end{aligned}\right.$

كه در آن

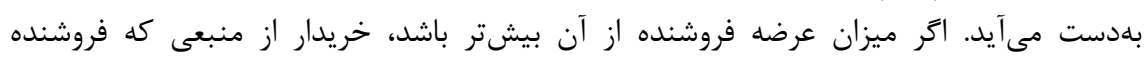

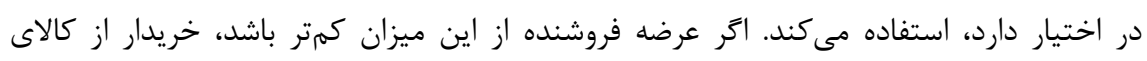

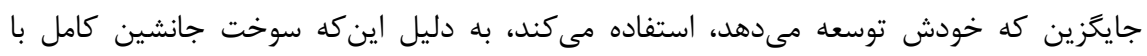
هزينه c در دسترس است. درآمد نهايى (t) است. از شرط اول هميلتونى يعنى نامعادله (1) (1) داريه: $q^{*}=\frac{1}{1+\alpha} \tilde{u}^{\prime-1}(c)$ ، $\leq \lambda(t)=\lambda_{T} e^{-r(T-t)}=f(\alpha) c e^{-r(T-t)}$

$T-t \leq-\frac{1}{r} \ln \left(\frac{\pi^{\prime}\left(q^{*}\right)}{f(\alpha) c}\right)$ با حل اين نامعادله براى t - T داريم:

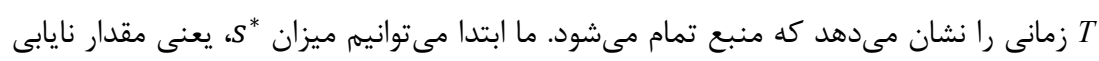

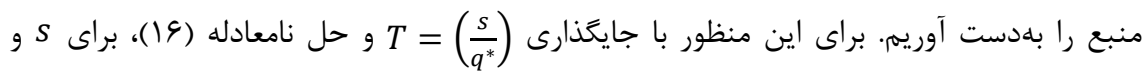
ماريم: 0

$s^{*}=-\frac{q^{*}}{r} \ln \left(\frac{\pi^{\prime}\left(q^{*}\right)}{f(\alpha) c}\right)$

براى حالتى كه فروشنده تا تمام شدن منبع با قيمتكذارى محدود روبهروست، براى همه عs

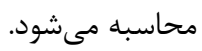

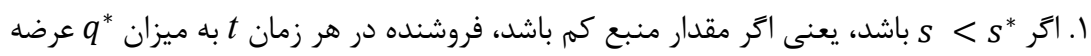

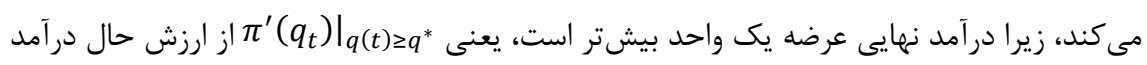

1. Transversality Condition

2. Scarcity Value of the Resource

3. Shadow Price 


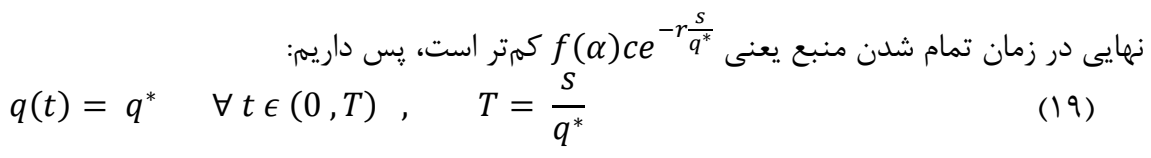
فروشنده در هر دوره تا زمان تمام شدن منبع، يعنى وقتى كه نامساوى زير براى همه

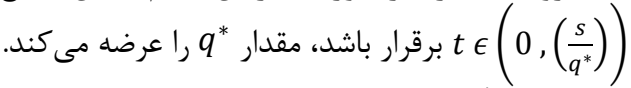

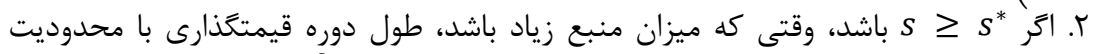
بلهقرى طول مى كشد تا منبع تمام شود، در اين حالت

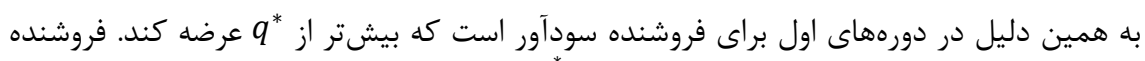

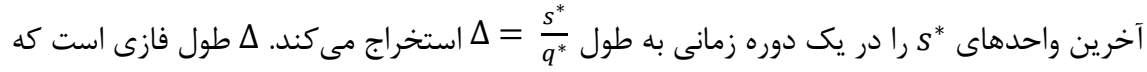

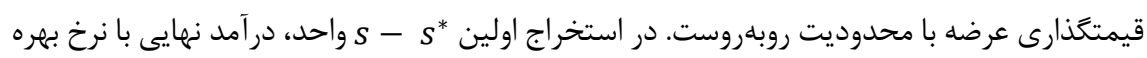

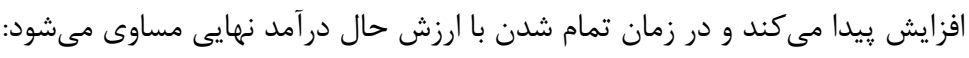
$\pi^{\prime}(q(t))=f(\alpha) c e^{-r(T-t)}$

$\Rightarrow q(t)=\left(\pi^{\prime}\right)^{-1}\left(f(\alpha) c e^{-r(T-t)}\right) \quad \forall t \in[0, T-\Delta]$ يعنى عرضه فروشنده را به عنوان تابعى از درآمد نهايى در نظر مى كيريم. براى زمانى كه با حذر

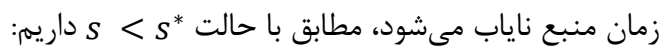

$q_{t}=q^{*}$ $\forall t \in[T-\Delta, T]$ مىتوانيم منبع در اختيار فروشنده را به صورت رابطه (r (T) بنويسيه: $\int_{0}^{T-\Delta}\left(\pi^{\prime}\right)^{-1}\left(c e^{-r(T-t)}\right)+\Delta q^{*}=s$ سيستم بالا ميزان عرضه بهينه فروشنده را بعد از سرمايهَذارى يعنى (S; $)$

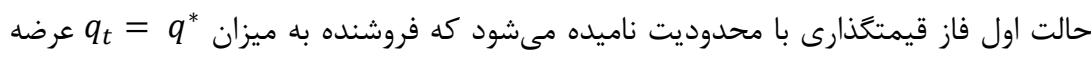
مى كند. در اين حالت، فروشنده نمى تواند مقدار كالايى كه عرضه مى كند را بيشتر از قيمت c بفروشد.

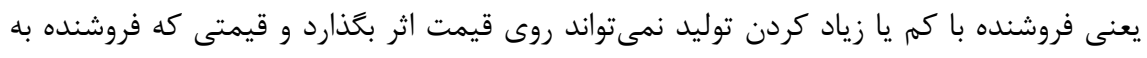

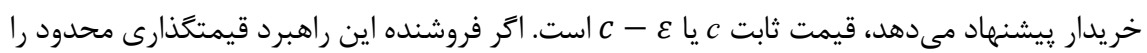
تا تمام شدن منبع اجرا كند، منبع در زمان است. اين حالت را در دو بخش $f(\alpha) c e^{-r \frac{s}{q^{*}}}$ عرضه فروشنده را در طول فاز بعد از سرمايه كذارى نشان مىدهد، كه از زمان صفر تا دان - 
به ميزان در اختيار، مقدارى كه فروشنده عرضه مى كند كاهش مىيابد، تا زمانى كه از شدن منبع يعنى T، فروشنده به ميزان

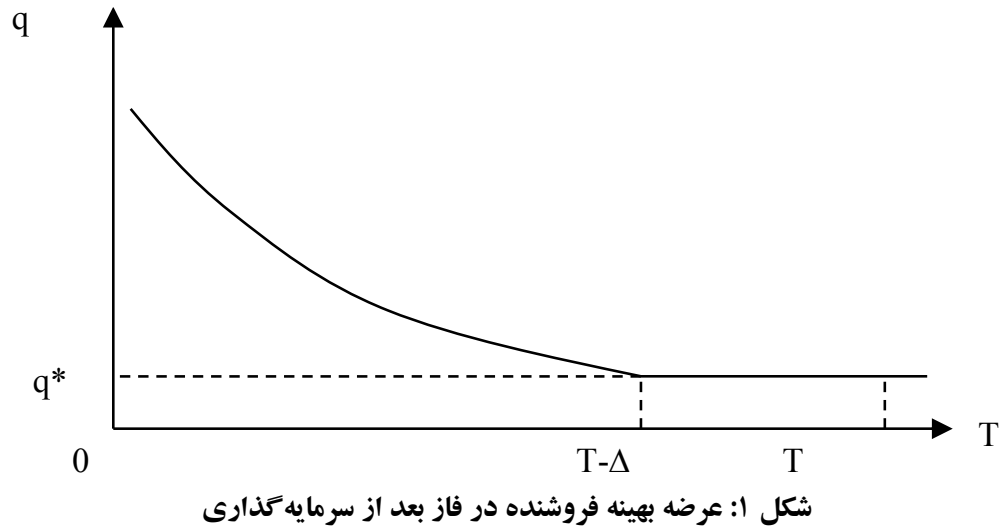

شكل (r)، ارزش حال درآمد نهايى را نشان مىدهد. با توجه به رابطه (D|) متوجه مىشويم كه

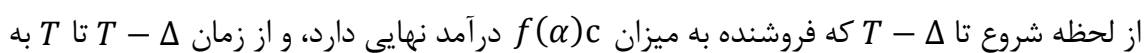
ميزان (t)

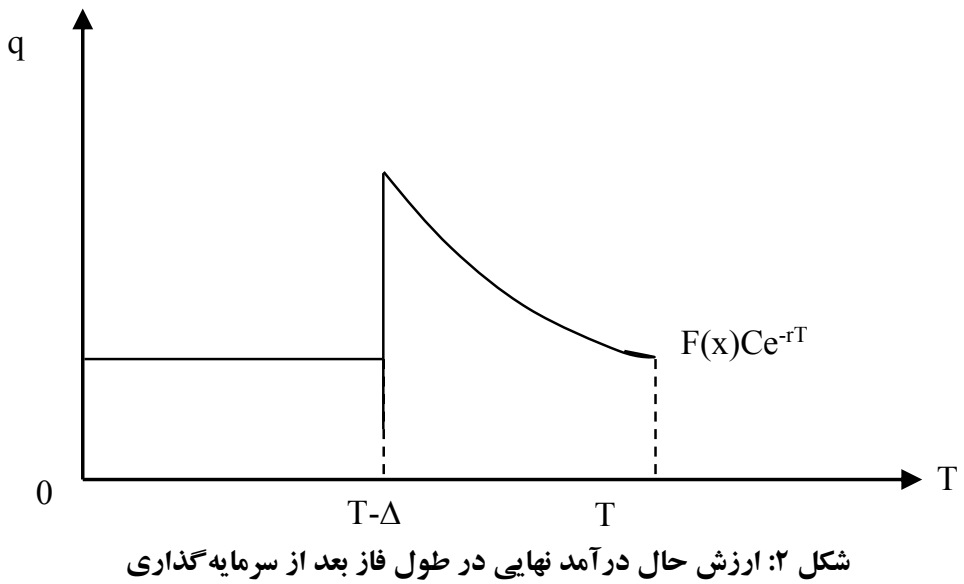


در تعادل، فروشنده بين عرضه يك واحد اضافهتر در هر دوره قبل از زمان قيمتخذارى با محدوديت

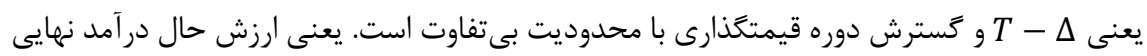
年 $f(\alpha) c e^{-r T} \pi^{\prime}\left(q^{*}\right) e^{-r t}$

در اين فاز، خريدار مقدار عرضه فروشنده را مشاهده مى كند و با توجه به آن تصميم مى گيرد كه

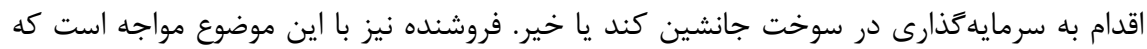

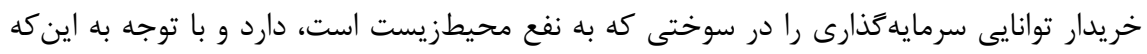
سوخت جانشين مطلوبيت بيشترى براى خريدار دارد، بايد مقدار و قيمت عرضه خود را مشخص كند. در مرحله قبل از سرمايه گذارى هر لحظه ممكن است خريدار تصميم به سرمايهگذارى بخيرد، يعنى هر لحظه ممكن است متغير حالت يعنى منبع تغيير كند و تا بىنهايت نمى تواند بر اساس زمان

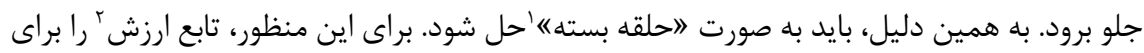

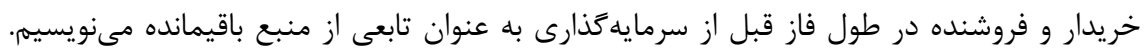

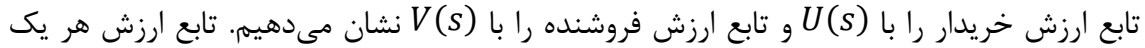

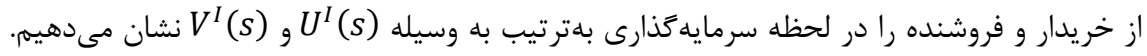
$q=\phi(s)$ دارد. منبع و مقدارى كه فروشنده عرضه مى كند بستخى دارد.

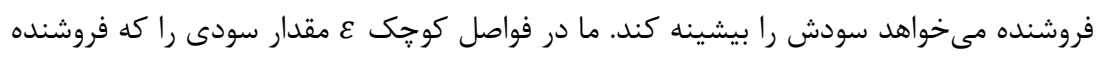
بهدست مى آورد، محاسبه مى كنيم. تابع ارزش براى فروشنده از انتخاب مقدار بهينه كه در فواصل كوجك ع عرضه مىشود، بهدست مى آيد:

$V(s)=\max _{\{q\}}\left\{\left[\varepsilon \pi(q)+e^{-\varepsilon r} V(s-\varepsilon q)\right](1-k(s, q))+V^{I}(s) k(s, q)\right\}$

با توجه به تابع ارزش (YF)، مى خواهيم بدانيم در بازههاى كوجى فروشنده جه مقدار بايد عرضه

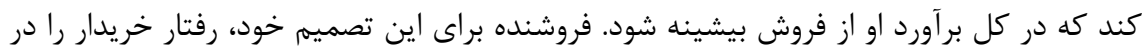


مورد اقدام به سرمايهگذارى در نظر مى گيرد. هدف خريدار بيشينه كردن مطلوبيتش از استفاده منبع

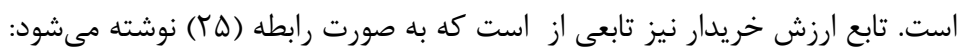

$U(s)=\max _{k \in\{0,1\}}\left\{\left[\varepsilon u(\phi(s))+e^{-\varepsilon r} U(s-\varepsilon \phi(s))\right](1-k)+U^{I}(s) k\right\}$

خريدار بايد اين تصميم را بخيرد كه سرمايهگذارى كند يا نه، و اين تصميم را بهگونهاى بخيرد

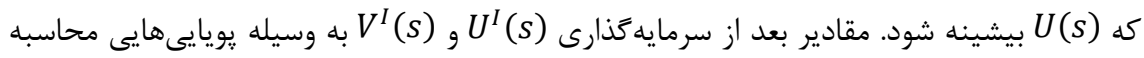
مىشوند. ما به دنبال يك جفت راهبرد تعادل براى كل S هستيه، بهطورى كه:

$\phi(s)=\arg \max _{\{q\}} V(s)$

$k(s, q)=\arg \max _{k} U(s)$

\section{نتايج مدل}

يس از حل مدل در حالت قبل از سرمايهگذارى، نتيجه نهايى كه از اين مدل بهدست مىآيد اين است

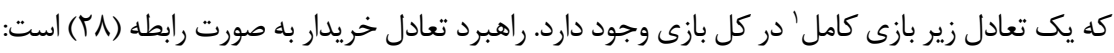
$k(s, q)=1 \quad \forall q: u(q)<u_{b}-r I$ $k(s, q)=0 \quad$ otherwise

تا به حال راهبرد خريدار به صورت $K=k(s, q)$ بود، اما اكنون مى

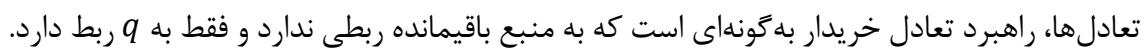

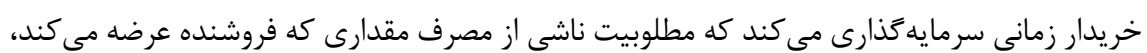

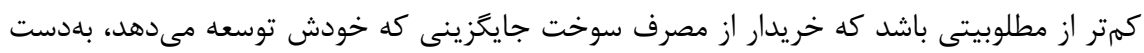
آورد. راهبرد تعادل فروشنده به صورت رابطه (9 بـ) است:

$\phi(s)=\phi^{I}\left(s ; \tilde{u}^{\prime}\left(u^{-1}\left(u_{b}-r I\right)\right)\right)$

كه توسط ( ) اخر حه انگگيزه در قبل و بعد از سرمايهگذارى متفاوت است، اما فروشنده هميشه به اندازه كمترين مقدار ذخيره خريدارَّ عرضه مى كند. در فاز بعد از سرمايه گذارى، عرضهكننده با اين موضوع كه

1. Subgame-Perfect Equilibrium

2. Buyer's Reservation Quantity 
خريدار خودش مىتواند مقدارى را توليد كند، مواجه است. بنابراين، در اين حالت عرضهكننده به

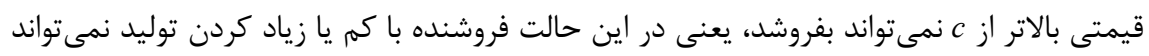

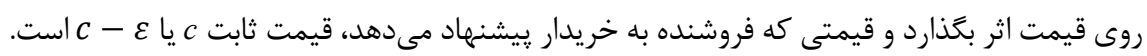

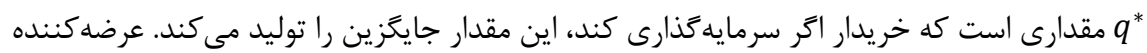

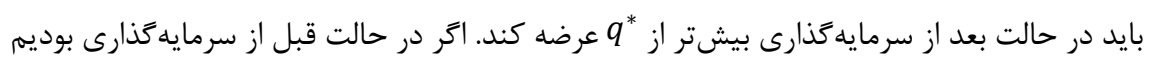

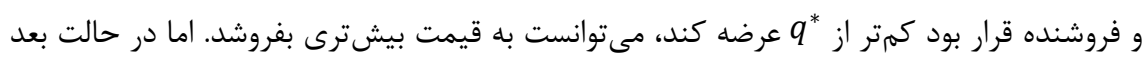

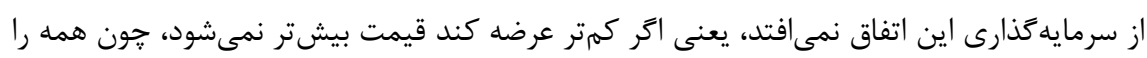

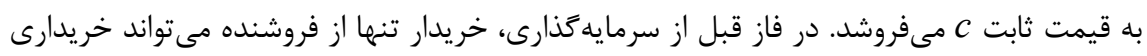

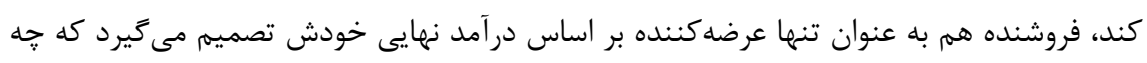

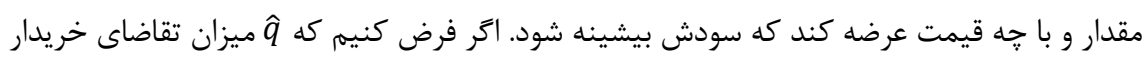
باشد و ميزان عرضه فروشنده $q$ باشد، فروشنده بايد بيشتر از تقاضاى خريدار عرضه كند كند تا خريدار

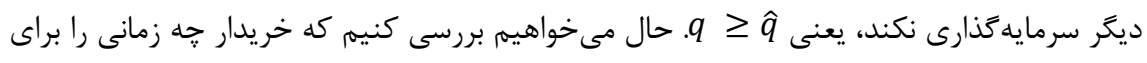
سرمايهَذارى انتخاب مى كند. اين بررسى منوط به مقايسه دو حالت است: حالت يكمم زمانى است

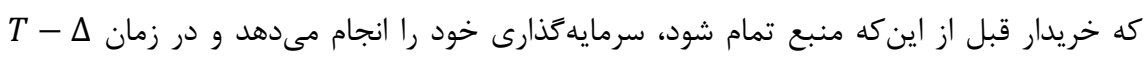

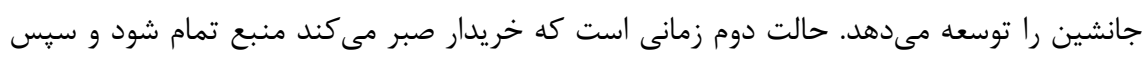

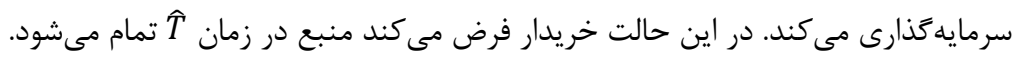

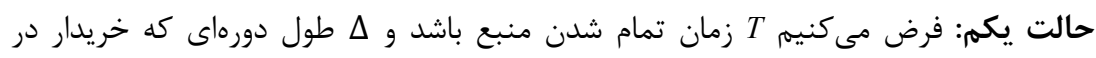

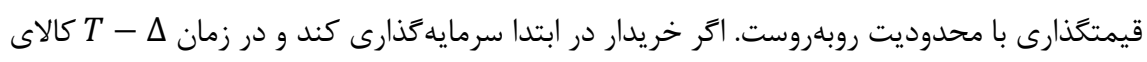

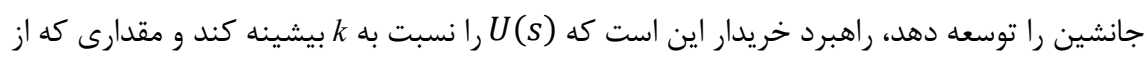

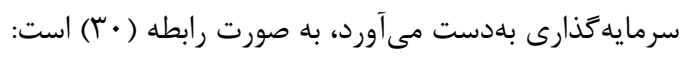
$\begin{aligned} U^{I}(s ; c) & =\int_{T-\Delta}^{\infty} u_{b}(c) e^{-r t} d t-I+\int_{0}^{T-\Delta} u_{s}\left(\phi^{I}(s ; c)\right) e^{-r t} d t \\ & =\int_{0}^{\infty}\left(u_{b}(c)-r I\right) e^{-r t} d t+\int_{0}^{T-\Delta}\left[u_{s}\left(\phi^{I}(s ; c)\right)-u_{b}(c)\right] e^{-r t} d t \quad(r \cdot)\end{aligned}$

$$
\begin{array}{r}
\dot{s}(t)=-\phi^{I}(s(t) ; c) \\
s(0)=s
\end{array}
$$

حالت دوم: احر فرض كنيم (ST) مجموع مازاد تنزيلشده خريدار (برآورد) باشد، در زمانى كه از 
راهبرد تعادل استفاده مى كند، يعنى اكر خريدار به اين موضوع فكر كند كه جه زمانى برايش بهصرفه

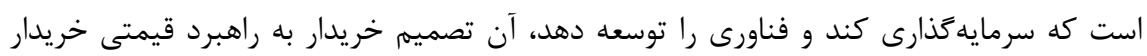

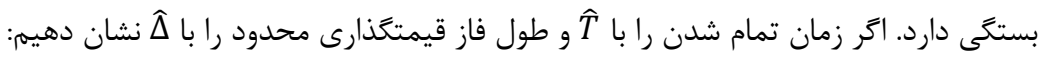
$\widehat{U}(s ; c)=\int_{\widehat{T}}^{\infty} u_{b}(c) e^{-r t} d t-e^{-r \widehat{T}} I+\int_{0}^{\widehat{T}} u_{s}\left(\phi^{I}\left(s ; \tilde{u}^{\prime}(\widehat{q})\right)\right) e^{-r t} d t$

$$
=\int_{\hat{T}}^{\infty}\left(u_{b}(c)-r I\right) e^{-r t} d t+\int_{0}^{\hat{T}} u_{s}(\hat{c}) e^{-r t} d t
$$

$$
=\int_{0}^{\infty}\left(u_{b}(c)-r I\right) e^{-r t} d t+\int_{0}^{\hat{T}}\left(u_{s}(\hat{c})-\left[u_{b}(c)-r I\right]\right) e^{-r t} d t
$$

$$
\begin{gathered}
\dot{s}(t)=-\phi^{I}\left(s(t) ; \tilde{u}^{\prime}(\widehat{q})\right) \\
s(0)=s
\end{gathered}
$$

قيمتى است كه وقتى فروشنده مقدار $\tilde{u}^{\prime}(\hat{q})=\hat{c}$ c $\geq c$ $U^{I}(s)=\int_{0}^{\infty}\left(u_{b}(c)-r I\right) e^{-r t} d t+\int_{0}^{T-\Delta}\left[u_{s}(c)-u_{b}(c)\right] e^{-r t} d t$ و براى حالت دوم داريم: - n

$$
\begin{aligned}
\widehat{U}(s)=\int_{0}^{\infty}\left(u_{b}(c)\right. & -r I) e^{-r t} d t \\
& +\int_{0}^{T-\Delta}\left(u_{s}(\hat{c})-\left[u_{b}(c)-r I\right]\right) e^{-r t} d t \\
& +\int_{T-\Delta}^{\hat{T}-\hat{\Delta}}\left(u_{s}(\hat{c})-\left[u_{b}(c)-r I\right]\right) e^{-r t} d t \\
& +\int_{\hat{T}-\hat{\Delta}}^{\hat{T}}\left(u_{s}(\hat{c})-\left[u_{b}(c)-r I\right]\right) e^{-r t} d t
\end{aligned}
$$




$$
\begin{aligned}
\widehat{U}(s)=\int_{0}^{\infty}\left(u_{b}-\right. & r I) e^{-r t} d t \\
& \left.+\int_{0}^{T-\Delta}\left(u_{s}(\hat{c})-u_{b}(c)\right) e^{-r t} d t+\int_{T-\Delta}^{\hat{T}-\widehat{\Delta}}\left(u_{s}(\hat{c})-u_{b}(c)\right) e^{-r t} d t\left(T^{\mu}\right)^{-}\right) \\
& +\int_{\widehat{T}-\hat{\Delta}}^{\hat{T}}\left(u_{s}(\hat{c})-u_{b}(c)\right) e^{-r t} d t+\int_{0}^{\hat{T}} r I e^{-r t} d t
\end{aligned}
$$

حال به مقايسه انتخرالهاى (SU) نظر مى گيريم. جون فرض مىشود C

$$
\text { دارد، يعنى }
$$

$\int_{0}^{T-\Delta}\left[u_{s}(c)-u_{b}(c)\right] e^{-r t} d t>\int_{0}^{T-\Delta}\left(u_{s}(\hat{c})-u_{b}(c)\right) e^{-r t} d t$

كه در آن (c) un مطلوبيتى است كه خريدار از مصرف كالايى كه خودش با هزينه c توسعه مى دهد، بلهدست مى آورد و us $u_{S}$ هم مطلوبيتى است كه خريدار از مصرف منبعى كه فروشنده عرضه مى كند، بهدست مى آورد. جون

$u_{s}(\hat{c})-u_{b}(c)<0$

$\int_{\hat{T}-\hat{\Delta}}^{\hat{T}}\left(u_{s}(\hat{c})-u_{b}(c)\right) e^{-r t} d t g \int_{T-\Delta}^{\hat{T}-\hat{\Delta}}\left(u_{s}(\hat{c})-u_{b}(c)\right) e^{-r t} d t$ منعى عبارت داخل انتخرالهاى منفى هستند. از طرفى،

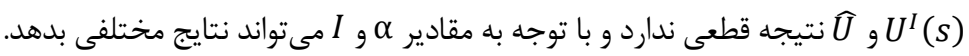

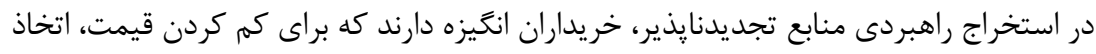

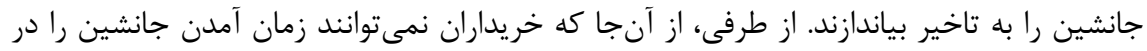

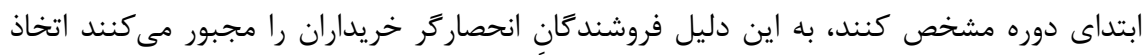

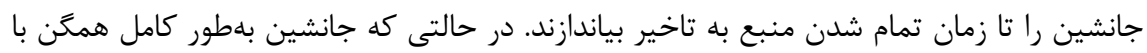

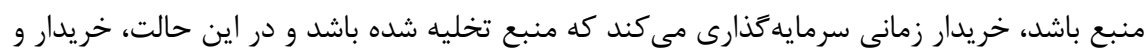

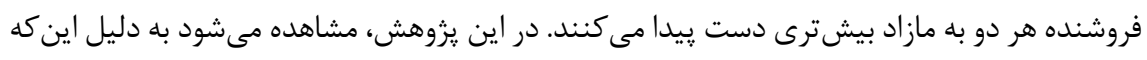

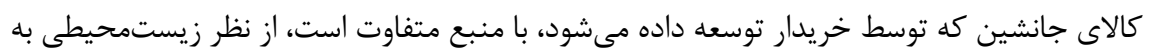


نفع محيطزيست است و در نتيجه مطلوبيت بيشترى براى خريدار بهوجود مى آورد. با در نظركرفتن

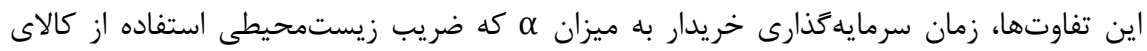

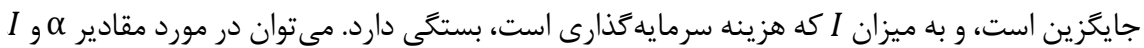

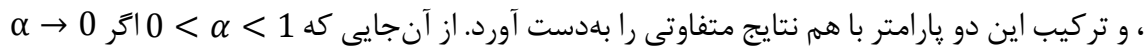

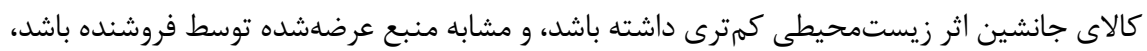

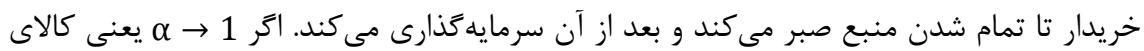

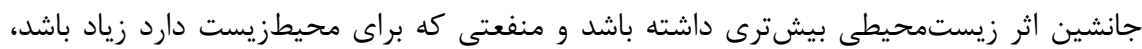

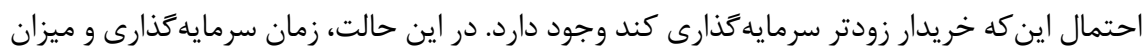
عرضه فروشنده به ميزان I مرتبط مىشود. هرجقدر ميزان هزينه ثابت براى سرمايه مَذارى كمرتر

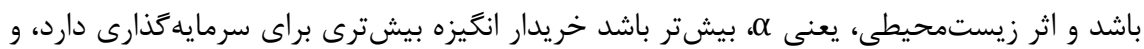

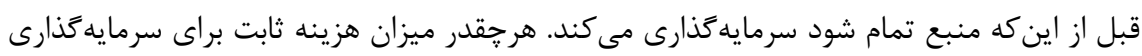

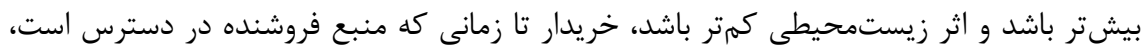
سرمايهخذارى را به تاخير مىاندازد.

\section{بحث و نتيجه}

اين يزوهش مى كوشد اثر سرمايهگذارى در كالاى جايخزين را كه در محيطزيست آلودگى ايجاد نمى كند، بررسى كند و نتيجه را با يروهش هايى كه بدون در نظركرفتن اهميت محيطزيست هستند، مقايسه نمايد.

در حالتى كه سوخت جايگزين و سوخت فروشنده بهطور كامل همخً باشند، تا زمانى كه منبع

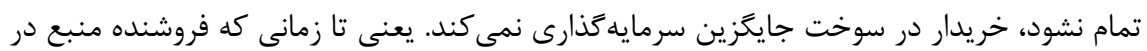
اختيار دارد، خريدار از فروشنده منبع خريدارى مى كند. در حالتى كه سوخت جايكزين با سوخت

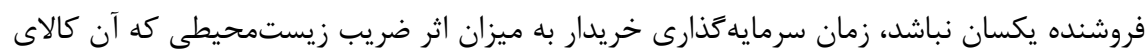

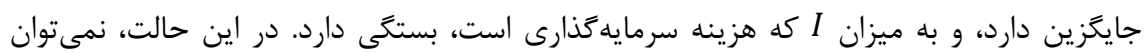
نتيجه قطعى در مورد زمان سرمايهَذارى خريدار گرفت و با توجه به مقادير ه و Iا، اين كه خريدار

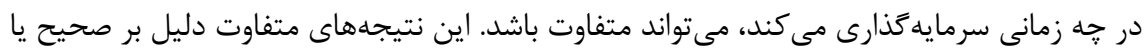

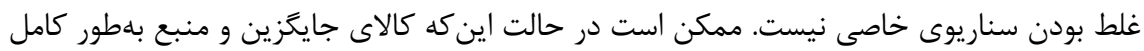


همگن باشند، خريدار كاز شيل' را براى جايكزين انتخاب كند و در حالتى كه سوخت جايكزين به نفع محيطزيست باشد، خريدار انرزى خورشيدى يا بادى را به عنوان كالاى جايگزين انتخاب كند، كه اين

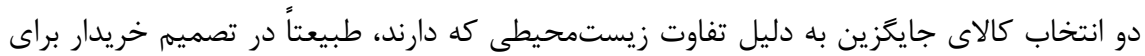

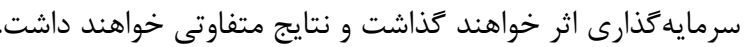

اصفهانى، حميده، و مهدوى زفرقندى، سعيده (ع بـ (). بررسى آثار رفاهى سياست زيستمحيطى واردات كالاى

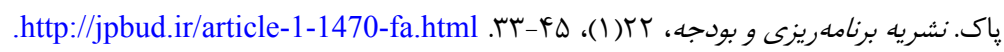

فدايى، مهدى، و مطفف، مرضيه (ه9 (1). روابط راهبردى بين كارتل عرضهكننده سوختهاى فسيلى

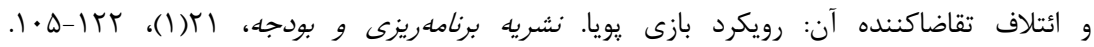
.http://jpbud.ir/article-1-1355-fa.html

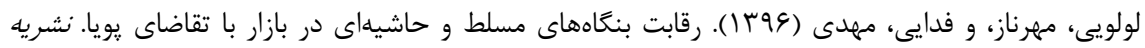

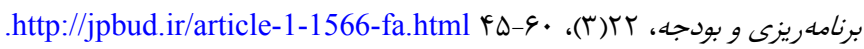

Gerlagh, R., \& Liski, M. (2011). Strategic Resource Dependence. Journal of Economic Theory, 146(2), 699727-. https://doi.org/10.1016/j.jet.2010.09.007.

Michielsen, T. O. (2014). Strategic Resource Extraction and Substitute Development. Resource and Energy Economics, 36(2), 455-468. https://doi.org/10.1016/j. reseneeco.2014.02.001.

Nordhaus, W. D. (1973). The Allocation of Energy Resources. Brookings Papers on Economic Activity, 4(3), 529-576.

Olsen, T. E. (1993). Perfect Equilibrium Timing of a Backstop Technology: Limit Pricing Induced by Trigger Zones. Journal of Economic Dynamics and Control, 17(1-2), 123-151. https://doi.org/10.1016/S0165-1889(06)80007-2. 